\title{
DA INTERAÇÃO AO DISCURSO NO ENSINO DE LÍNGUA MATERNA
}

\author{
Eleni Jacques Martins
}

\begin{abstract}
RESUMO: Cet article discute l' importance d'adopter une concpcion pragmatique du langage dans l'enseignement de la langue maternelle. L' hypothèse sur laquelle cet étude s'appui s'origine d'um concept de dialogue élaboré à partir de la critique de la notion de dialogie du sens commun et de théories de l'énontiation e du discours. Pour le developpement des points de vue soutenus, on prend comme exemple la "pedagogie" de Mr. Higgins, personnage de la pièce "Pygmalion" de Bernard Shaw.
\end{abstract}

PALAVRAS-CHAVE: ensino-aprendizagem, Pragmática, enunciação, diálogo, linguagem, ação lingüística.

Meu tema ${ }^{1}$ é o papel do diálogo no processo ensino-aprendizagem. Ao desenvolvê-lo, vou defender a adoção de uma perspectiva pragmática da linguagem como orientadora do ensino do Português. Contraporei essa perspectiva a uma outra que me parece ainda predominar em nossas escolas e à qual atribuo um caráter monológico, pouco produtivo, por basear-se em pressupostos lingüísticos e pedagógicos equivocados.

Para desenvolver a discussão do meu tema, me apoiarei numa noção própria de diálogo, que será explicitada mais adiante, e tomarei como caso exemplar a aventura pedagógica vivida pelo Professor Higgins, Eliza e o Coronel Pickering, que constitui o núcleo dramático da peça "Pigmalião" de Bernard Shaw. Esse é um texto clássico da literatura ocidental: Bernard Shaw retoma a história de Pigmalião e Galatéia, um dos mitos fundadores do espírito grego, e que ainda impregna nossa fantasia de homens e mulheres modernos. Em algum ponto

Eleni Jacques Martins foi professora do Instituto de Letras da UFRGS. Faleceu em janeiro de 1997.

${ }^{1}$ Texto inédito no Brasil. Publicado anteriormente em Portugal. 
obscuro da mente, conservamos a fantasia de objetivamente moldar o outro, e os alunos certamente são nosso alvo privilegiado.

Como no mito grego em que Pigmalião, todo poderoso, esculpiu sua mulher ideal, o Professor Higgins decidiu transformar a rude Eliza numa grande dama. Para ser mais fiel à história. Mr. Higgins empenhou-se em livrar-se dos traços populares e incultos da personagem Eliza, que o repugnavam, com o mesmo egocentrismo com que Pigmalião pretendeu criar uma mulher que estivesse acima das características do sexo feminino, que ele deplorava. Nada de muito interessante para nós, não fosse o fato de que o milagre da criação deveria dar-se pela mudança de linguagem. $\mathrm{O}$ drama envolverá três personagens, que se encontram por acaso numa rua de Londres, em noite de chuva. A primeira personagem é meu interlocutor, um famoso professor de fonética e defensor apaixonado da pureza e excelência no desempenho lingüístico. A segunda personagem é Eliza, uma jovem florista que vaga abandonada pelas ruas e cuja linguagem apresenta as características de sua condição social miserável, isto é, extremamente distanciada da linguagem culta, a considerada língua padrão. Segundo as palavras de seu futuro mestre, ela emite grunhidos insuportáveis ao falar. A terceira personagem é o Coronel Pickering que não interpelo como o primeiro, por respeito a sua natureza que é de manter-se à sombra, uma espécie de "alter ego" de Mr. Higgins.

Mr. Higgins é um professor que não só treina lingüisticamente as pessoas para integrarem-se a ambientes sociais mais elevados que o de sua origem, como expressa radical aversão pela linguagem inculta dos segmentos não escolarizados da sociedade. Num dos primeiros diálogos que mantém com Eliza, ao ouvi-la falar, ele lhe diz: "Uma pessoa que pronuncia as palavras tão mal como você não tem o direito de ficar em parte alguma. Não tem o direito de viver. Lembre-se de que sua língua materna é a língua de Shakespeare". Essa tirada faz parte do comportamento verbal de Mr. Higgins, sempre entre irritado e irreverente. Em todo caso, expressa a intransigência do professor em relação àqueles que ousam ter fala diferente. Já o Coronel Pickering tem seu interesse voltado não para a hegemonia da língua culta, mas para a diversidade dos falares, pois é um dialetólogo. É interessante guardar a diferença entre os dois porque ela mostrará sua importância na história do aprendizado de Eliza. Para ressaltar esse aspecto, conduzirei a aventura dos três a um tipo de aproximação (talvez não planejada por Bernard Shaw) com o mito de Pigmalião e Galatéia. Minha estratégia para tanto será a de retirar o Coronel Pickering da obscuridade e fazer ver nele um possível simulacro da deusa Vênus, que, no mito, também é o vértice menos aparente do triângulo, embora no caso seja a detentora da chama da vida. Mas esse é um tema que se desenvolverá mais tarde.

Dito isso, retomo nossa história. Ela efetivamente começa quando, no dia seguinte ao encontro a que me referi acima, Eliza procura Mr. Higgins, pedindo que ele a ensine a falar, pois quer arrumar um emprego e ninguém a aceita porque não "sapeca o verbo em condições". (Neste momento e nos outros em que faço referência a falas dos personagens, cito o texto traduzido por Rachel de Queiroz). Mr. Higgins, aparentemente, não se preocupa com as aspirações de Eliza, mas 
aceita-a como aluna porque havia apostado com o Coronel Pickering, na noite anterior, que, em três ou seis meses, transformaria de tal forma sua linguagem que suas maneiras também se modificariam e ela passaria por uma grande dama em qualquer reunião de sociedade.

Esses dados sobre "Pigmalião" bastam para apresentar meu interlocutor e seus parceiros de jornada pedagógica. Devo, agora, tecer algumas considerações sobre minha afirmação inicial de que a concepção de ensino de linguagem predominante em nossas escolas é monológica e de que seria preciso uma mudança de pressupostos teóricos para criar uma pedagogia dialógica e mais eficiente.

Nos ambientes escolares que se consideram mais esclarecidos, a chamada gramática tradicional caiu em desgraça. Virou objeto de escárnio e mal-dizer por ser normativa, antiga e incoerente (e mais incoerente fica, é verdade, a cada tentativa de modernização). Assim, hoje, na falta da gramática que era a base do ensino, ou se ensina uma coisa chamada comunicação, ou nada se ensina, ou se tenta apelar para a lingüística, essa poderosa e sofisticadíssima vizinha da própria gramática.

As correntes mais fortes da lingüística moderna como a lingüística estrutural e a gramática gerativa não propõem métodos pedagógicos, mas por seu prestígio e às vezes má interpretação dos estudiosos, têm reforçado tendências monológicas do ensino. Muitos professores tomam um dos níveis da gramática, geralmente a morfologia e a sintaxe e fazem disso único objeto de ensino, passando a trabalhar com uma metalinguagem que bloqueia o diálogo enquanto promotor do desenvolvimento lingüístico. Isso porque o trabalho com essa metalinguagem assume o caráter de informação sobre a estrutura e classificação das palavras ou sobre a sintaxe. E a informação tem um caráter unidirecional, de um "eu” para um "tu”, sem que se pressuponha, necessariamente, uma interação dialógica, que podemos entender aqui como uma reciprocidade semântica e responsiva entre os interlocutores.

Mas o problema pedagógico maior não é, ainda, o de apelar para o estruturalismo ou para a gramática transformacional, pois esse pode ser contornado pelo adequado aproveitamento de algumas noções de grande poder explicativo. $\mathrm{O}$ problema se torna sério quando, por falta de domínio dessas teorias ou por impossibilidade de trazê-las ao nível dos alunos, utilizamos apenas algumas de suas técnicas, e descontextualizadas. Por exemplo, quando usamos exercícios de estruturas frasais para treinamento, ou nos dedicamos a representações arbóreas de frases com o intuito de substituir a antiga análise sintática. E este é o enquadramento metodológico do Professor Higgins. Vê-se que, embora declare ser especialista em fonética, que ele chama de ciência do discurso, seu trabalho se resume a técnicas de treinamento de certas estruturas fonológicas e gramaticais.

De outro lado, há correntes atuais de estudo da linguagem, não centradas na língua ou na competência, mas interessadas em criar sistemas para a análise das relações enunciativas. É um amplo espectro de investigação, que, para simplificar, englobarei sob o rótulo "Pragmática". Evidentemente não vou propor que se 
substitua o ensino da gramática pelo de alguma teoria prgmática, porque, nesse caso, não estaríamos contribuindo em nada para evitar aquilo que entendo como procedimentos monológicos de ensino. O que pretendo é ressaltar a relevância da qualidade das "relações enunciativas" no processo pedagógico.

Da mesma forma, não proponho o abandono do estudo da língua portuguesa como sistema ou como processo gerativo de frases, ou, ainda, como conjunto de normas porque, mais do que nunca, precisamos propiciar ao aluno o domínio do português culto. Constituiremos uma nação muito pobre se não tivermos, entre os princípios fundadores de nossa cultura, um ideal de língua a ser buscado, até mesmo como fazia o Professor Higgins, por meio de um orgulho apaixonado, imaginário talvez, de sua excelência.

Não estou contestando conteúdos de ensino. Quando, no título, afirmei ao Professor Higgins que era preciso aprender a linguagem, não the quis dizer que abandonasse a língua, mas que fizesse de suas aulas, em todas as circunstâncias de ensino, aulas também de linguagem. Que seu ensino não seja meramente informativo e de treinamento do aluno no uso de formas de expressão oral e escrita impostas. Pedia-lhe que não tratasse a língua apenas como um objeto de conhecimento entre outros e que não considerasse o aluno como matéria neutra a ser moldada lingüisticamente.

Finalmente, espero que o Professor Higgins tenha entendido que, embora o conhecimento da língua seja fundamental, para o aluno o desempenho lingüístico satisfatório é tudo. Sugiro, então, que o Professor lhe dê a oportunidade de construir-se lingüisticamente e que, com essa atitude, se livre, ele mesmo, da síndrome de Pigmalião. Caso se decida por isso, lhe será útil buscar alguns subsídios para seu trabalho nessa extensa área do conhecimento lingüístico que se chama Pragmática. Nascida em 1938, quando Charles Morris a definiu como a parte da semiose que trata da relação linguagem-intérprete (e usuário), sua existência já era reivindicada em 1992 por Bakhtin, ao afirmar que "a verdadeira substância da linguagem não é a constituída por um sistema abstrato de formas lingüísticas, nem pela enunciação monológica isolada, mas pelo fenômeno social da interação verbal, realizada através da enunciação" (BAKHTIN, 1984).

Mas, como já disse, se trago a pragmática como perspectiva teórica a ser considerada nas aulas de língua materna, não é para transformá-la em conteúdo de ensino. Invoco-a porque ela trata da interação lingüística, e, quando se que lidar com processos dialógicos, é no seu âmbito que nos devemos colocar.

Dito isso, devo explicitar qual a concepção de diálogo que utilizo, sob pena de incorrer em grave imprecisão, pois, pelo constante uso que se faz desse termo na vida cotidiana e na própria lingüística, ele tornou-se extremamente vago. Não utilizarei o termo diálogo no sentido comum de ação lingüística que cumpre intenções de entendimento porque, nesse caso, me colocaria numa perspectiva psico-social de investigação e o meu interesse é lingüístico. Também não utilizarei o termo na acepção que lhe dão as teorias do discurso, porque, segundo os discursivistas, toda relação enunciativa é dialógica, visto que se dá entre um "eu" e 
um “tu”. E nesta perspectiva, eu não poderia dizer que algumas relações lingüísticas são dialógicas e outras não, bem como não poderia afirmar que há relações de ensino não dialógicas.

Então, para evitar imprecisões ou generalidades, utilizo uma concepção própria de diálogo, formulada em trabalho anterior (MARTINS, 1990), no qual considero a enunciação e o diálogo como duas noções diversas, embora teoricamente interdependentes. Desse ângulo, toda enunciação é interpessoal, mas nem toda relação enunciativa é dialógica. O diálogo seria uma peculiaridade semântico-pragmática da enunciação, configurada na intersubjetividade do relacionamento. E essa intersubjetividade ocorreria quando os interlocutores se relacionassem com igual poder da palavra.

Para tornar essa definição de diálogo metodologicamente viável, propus uma estrutura de enunciação em dois níveis. O primeiro nível é o do discurso, no qual os interlocutores se constituem como lugares sociais pelos contextos discursivos que criam. O segundo nível é o da ação lingüística no qual, pelas ações que praticam (ações de negar, afirmar, interrogar, fazer ironias, argumentar, etc...), os interlocutores confirmam ou alteram as relações estabelecidas no primeiro nível. O diálogo não é um terceiro nível, mas um ponto de equilíbrio do poder da palavra nesse esquema de enunciação em dois níveis. O diálogo se estabelece, portanto, quando, no nível discursivo, os interlocutores falam a partir de contextos discursivos que dominam e/ou aceitam e, no nível da ação lingüística têm as mesmas oportunidades de agir, ou seja, têm as mesmas oportunidades de tomar a palavra e praticar com ela todos os jogos que a língua permite. Há diálogo portanto, quando, pelo equilíbrio de poder da palavra, os interlocutores podem representar-se como sujeitos de seu dizer.

Neste estágio de minha explanação, constato o que de certa forma já esperava. Vejo o Professor Higgins cético e pronto a dizer que, do ponto de vista que defino o diálogo, meu projeto de dialogia no ensino é inviável. Tentará me convencer de que, na relação pedagógica padrão, existe um desequilíbrio de poder da palavra, na medida em que o professor é obrigado a implantar um contexto discursivo científico ou de outra natureza, que constituirá o contexto pedagógico no qual o aluno terá que movimentar-se em situação de desvantagem. Explicará que, por constituir matéria de ensino, esse contexto será construção semântica do professor, que deverá impô-lo ao aluno, pois de outro modo se desfiguraria a relação pedagógica. Concluirá, afirmando que, por isso, meu projeto de ensino dialógico é utópico: a relação professor-aluno será sempre monológica na minha perspectiva de diálogo como equilíbrio do poder da palavra. Visto que o poder é do professor. E, perdida a possibilidade do equilíbrio, não haveria, segundo $\mathrm{Mr}$. Higgins, inconveniente em ater-se, em aula, a boas técnicas de treinamento, o que, nas circunstâncias, seria até mais honesto.

Devo confessar que o argumento do Professor Higgins é forte e, como sou pelo menos vocacionada ao diálogo, aceito-o, mas com restrições. Meu conceito de 
enunciação é mais dinâmico que o dele e por isso me oferece a saída que ele não encontra para as determinações monológicas do discurso pedagógico.

É verdade que certos discursos, entre eles o pedagógico, são verdadeiras grelhas pragmáticas onde se cristalizam as relações de poder da palavra. Mas a enunciação, como a entendo, não se reduz a um único nível, o discurso, onde se constituem os significados e as relações lingüísticas. Proponho um segundo nível, o da ação lingüística, a partir do qual se podem trabalhar os significados e alterar as relações estabelecidas pelos discursos. Sendo admitido e respeitado como interlocutor, o aluno, por sua ação lingüística, poderá, aos poucos, apropriar-se dos discursos e de seus poderes. Entretanto se o professor o tomar apenas como destinatário de informação ou objeto de amestramento, é possível que o aluno permaneça, do ponto de vista de sua aprendizagem, um destituído da palavra.

Retorno à experiência de meu interlocutor, que afinal, é meu caso exemplar, na busca de maior consistência para meus argumentos. Pelas intenções declaradas do professor, as aulas de Eliza seriam de fonética, sua especialização, mas, pelas transformações que no decorrer da ação se observam na fala da aluna, verifica-se que o ensino envolveu também a morfologia e a sintaxe. Mas, no teste a que foi submetida a aluna quando, pela primeira vez, foi apresentada à sociedade, fica claro, pelo menos aos olhos do espectador, que o treino de fonética e a imposição de um vocabulário refinado e de uma sintaxe padrão não foram suficientes para o projeto de criação de uma Eliza adequada à linguagem da alta sociedade. $\mathrm{O}$ fracasso se manifesta de duas formas. Primeiro, a aluna se restringe à repetição de algumas frases ensaiadas, comportando-se como um papagaio bem treinado. Segundo, quando ela se liberta dessa condição e assume realmente a palavra, pelo conteúdo semântico de seu discurso revela sua origem de mulher de rua, representante do mais baixo escalão sócio-econômico, embora continue pronunciando as frases dentro dos padrões fonéticos, morfológicos e sintáticos que lhe foram ensinados.

Esse é um paradoxo que o Professor Higgins não conseguiu resolver. Ou sua aluna não interage lingüisticamente, restringindo-se à repetição automatizada de algumas frases, bem articuladas, é verdade, ou, quando se relaciona, revela pela linguagem, exatamente aquilo que deveria ser ocultado, sua verdadeira condição social. O conteúdo ideológico-semântico de seu discurso configura seu verdadeiro lugar social, embora ela continue seguindo os ensinamentos do mestre. Confirmase, assim, a razão de minha advertência inicial ao Professor Higgins: o ensino baseado exclusivamente na língua ou, pior ainda, no treinamento para a aquisição de certas formas lingüísticas pode transformar-se numa relação monológica com efeitos catastróficos para o desenvolvimento lingüístico do aluno.

Concordo com o Professor Higgins que, em seu trabalho com Eliza, se estabeleceria, no nível discursivo, uma relação de desequilíbrio se ele estabelecesse um contexto discursivo como sustentação de seu trabalho pedagógico. Ela seria a parte desfavorecida nesse nível porque tal contexto estaria ligado a conhecimentos e técnicas lingüísticas que a aluna, enquanto tal, não conheceria e no qual não 
poderia movimentar-se semanticamente. Mas o problema de desequilíbrio poderia, aos poucos, ser superado a partir da ação lingüística se o professor lhe atribuísse o papel de interlocutora. Nesse caso, ele estaria dando-lhe a oportunidade de agir lingüisticamente, o que lhe permitiria, aos poucos, inserir-se naquele contexto e dele compartilhar, tornando-o seu na medida em que progredisse em seu aprendizado. Entretanto, quando assistimos ao teste de Eliza para dama da sociedade, vimos que nada disso aconteceu. Apesar de ostentar símbolos da alta burguesia, como vestuário, gestos e até mesmo símbolos de natureza lingüística, como uma prosódia e sintaxe peculiares, a aluna se mostra, por seu discurso uma garota da rua e não dos salões da alta sociedade londrina. Progrediu pouco sua aluna, Professor Higgins... .

Viu-se, através da história do Professor Higgins e Eliza e também do Coronel Pickering, que ainda não apareceu à luz, que, numa pedagogia de língua materna, desenvolvida monologicamente, o sucesso do professor seria, contraditoriamente, seu fracasso. Explico: o ensino do português baseado unicamente na transmissão de padrões gramaticais ou prosódicos, se bem sucedido, transformaria o aluno num bom articulador de frases apenas e, consequentemente, em mero repetidor de um discurso alheio, ou sem discurso nenhum. Em decorrência disso, ele perderia sua identidade social e a capacidade de representarse frente aos outros como sujeito lingüístico.

O Professor Higgins me dirá que isso não é verdade porque Eliza acabe adquirindo independência em relação a ele e tornando-se lingüisticamente uma dama como ele esperava. E eu lhe digo que isso não foi obra sua, mas de seu companheiro, Coronel Pickering, que sempre interagiu lingüisticamente com ela. Nosso dialetólogo, acostumado a todos os falares, manteve uma relação de respeito com Eliza. Jamais viu nela uma aberração lingüística ou social. Sempre interagiu com ela na condição de interlocutora, criando desse modo um contexto de ação lingüística favorável ao seu desenvolvimento discursivo, através do qual ela pôde ascender ao lugar social que almejava.

Esse aspecto não emerge explicitamente na peça. Como o próprio Coronel Pickering, permanece em nível subjacente da ação dramática. Mas tem suas evidências em alguns momentos. Sobretudo quando a discípula declara aquilo que já afirmei, ou seja, que não foi Mr. Higgins, mas seu amigo que a ajudou, tratandoa por "senhorita". Subentende-se através disso, que, graças à ação lingüística do Coronel Pickering, Eliza pôde progressivamente passar do universo discursivo em que atuava lingüisticamente como garota abandonada para o universo discursivo onde atuará a moça bem colocada socialmente.

É ao atribuir ao discreto Coronel Pickering a condição de sustentáculo do progresso lingüístico de Eliza que aproximo, bem mais do que talvez pretendesse Bernard Shaw, sua peça do mito de Pigmalião e Galatéia. Para tornar evidente o paralelo, apresento um trecho do mito narrado por Ovídio. E, assim, apoiando-me nos poderes mágicos do teatro, do cinema e da poesia, esforço-me para dar maior clareza ao meu pensamento. 
"Pigmalião, com arte e engenho admiráveis, esculpiu em níveo marfim, uma figura de uma beleza que nenhuma mulher pode ter e apaixonou-se por sua obra. Muitas vezes suas mãos a apalpam para constatar se ela é de carne ou de marfim, e, não quer se convencer que é marfim. E ora a cobre de carícias, ora traz-lhe presentes, como se faz com as mulheres: conchas, pedras polidas, passarinhos e flores de mil cores $(\ldots)$

"Mas chegara o dia da festa de Vênus, celebrada por toda a população de Chipre. Pigmalião se aproximou dos altares e disse timidamente 'Se tudo podeis dar, ó deuses, eu desejaria que fosse minha esposa - não se atrevendo a dizer - donzela de marfim - , completa: parecida com minha - donzela de marfim'. A própria Vênus, que estava presente à festa, recoberta de ouro, percebeu o que queria dizer a súplica, e, como presságio favorável, a chama se ascendeu três vezes e uma língua de fogo correu pelo ar.

Quando regressou, Pigmalião procurou sua estátua de mulher e, debruçando-se sobre o leito, beijou-a. Pareceu-lhe tépida. Aproxima a boca de novo, apalpa-lhe o peito: ao contato, o marfim se amolece, cede sob a pressão dos dedos. Então, tomado de espanto, e, alegre e apreensivo ao mesmo tempo, temendo ter-se enganado, o amante estende de novo a mão e apalpa de novo o cobiçado objeto. Era um corpo humano". (OVÍDIO, 1983. Excertos.)

Por Galatéia e por Eliza meu reconhecimento à Vênus e ao Coronel Pickering. Mas meu respeito também a Pigmalião e ao Professor Higgins. Não foi inútil o talento de Pigmalião ao esculpir uma mulher de tão grande beleza, embora tenha sido necessária a intervenção de Vênus para trazê-la à realidade e tirá-lo da solidão. Também não foi inútil o trabalho de Mr Higgins. Praticar corretas estruturas gramaticais e a boa pronúncia da língua culta faz parte do universo discursivo que é o de Eliza no final da peça. Contudo ela não o teria atingido sem a ação lingüística que lhe proporcionou o Coronel Pickering. Através dela pode desenvolver-se lingüisticamente e quebrar o monólogo de seu professor.

Por um desígnio das musas da dramaturgia, Vênus e Pigmalião são dois personagens na relação com Galatéia, que lhe permitiu transformar-se de estátua em mulher. Por desígnios semelhantes, o Professor Higgins e o Coronel Pickering são dois personagens envolvidos no aprendizado de Eliza. Mas, em favor dos estudantes, invoco os deuses e dirijo-lhes a súplica de que os dois sejam uma só pessoa em cada professor de língua portuguesa.

\section{BIBLIOGRAFIA}

BAKHTIN, M. ( Volochinov). Marxismo e filosofia da linguagem. São Paulo, Huicitec, 1981a.

MARTINS, E. J. Enunciação e diálogo. Campinas, Ed. da Unicamp, 1990. 
MORRIS, C. W. Fundamentos da teoria dos signos. Rio de Janeiro, Eldorado Tijuca, USP, 1976.

OVÍDIO. As metamorfoses. Traduzido por David Jardim Júnior. Rio de Janeiro, 1983.

SHAW, B. Pygmalion. London, Longman, 1983. 